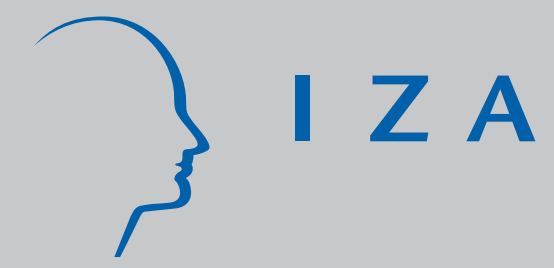

IZA DP No. 1988

Geographic Proximity, Trade and International Conflict/Cooperation

J ohn Robst

Solomon Polachek

Yuan-Ching Chang

February 2006 


\title{
Geographic Proximity, Trade and International Conflict/Cooperation
}

\author{
John Robst \\ University of South Florida \\ Solomon Polachek \\ State University of New York at Binghamton \\ and IZA Bonn \\ Yuan-Ching Chang \\ Chinese Cultural University, Taiwan
}

Discussion Paper No. 1988

February 2006

IZA
P.O. Box 7240
53072 Bonn
Germany

Phone: +49-228-3894-0

Fax: +49-228-3894-180

Email: iza@iza.org

\begin{abstract}
Any opinions expressed here are those of the author(s) and not those of the institute. Research disseminated by IZA may include views on policy, but the institute itself takes no institutional policy positions.

The Institute for the Study of Labor (IZA) in Bonn is a local and virtual international research center and a place of communication between science, politics and business. IZA is an independent nonprofit company supported by Deutsche Post World Net. The center is associated with the University of Bonn and offers a stimulating research environment through its research networks, research support, and visitors and doctoral programs. IZA engages in (i) original and internationally competitive research in all fields of labor economics, (ii) development of policy concepts, and (iii) dissemination of research results and concepts to the interested public.
\end{abstract}

IZA Discussion Papers often represent preliminary work and are circulated to encourage discussion. Citation of such a paper should account for its provisional character. A revised version may be available directly from the author. 
IZA Discussion Paper No. 1988

February 2006

\section{ABSTRACT}

\section{Geographic Proximity, Trade and International Conflict/Cooperation ${ }^{*}$}

This paper examines the interactive effect of distance and trade on international conflict and cooperation. The effect of geographic distance depends on trade, while the effect of trade varies with geographic distance. Trade reduces conflict to a greater extent when dyads are geographically close, but has a greater effect on cooperation when countries are more distant. Geographic proximity increases conflict and cooperation more among non-trading dyads.

JEL Classification: $\quad A 12, A 13, F 1,057$

Keywords: conflict, trade, distance, geographic proximity, cooperation, international relations, international interactions

Corresponding author:

Solomon Polachek

Department of Economics

State University of New York at Binghamton

Binghamton, NY 13902

USA

Email: polachek@binghamton.edu

\footnotetext{
* We appreciate the helpful comments from Glenn Palmer and four anonymous referees. An earlier version of this paper was presented at the Peace Science Society Meetings in Ann Arbor, Michigan, 2003.
} 


\section{Introduction}

Studies of international conflict frequently disagree on the causes of war. However, one factor consistently found to enhance a war's likelihood is geographic proximity (Diehl, 1991). Closer countries fight more than distant countries. There exist several potential reasons for this relationship (Vasquez, 1995). First, it may be difficult or even impossible for distant countries to fight each other, mainly because military operations become expensive at great distances. This is particularly true for small or less developed countries. Second, closer countries have more territorial disputes, leading to more conflictive behavior. Territorial disputes may involve resources contained in a given territory that affects a state's willingness to fight (Barbieri and Petersen, 2001). Third, and most relevant to our paper, closer countries interact more by nature of their proximity. More interactions provide an opportunity for more conflicts of interest, which can result in more rivalry and strife. Such incentives for conflict contradict neoliberal strands of thought, namely that the greater trade exhibited by closer countries should reduce conflict. This leads to a paradox: On one hand, geographic proximity intensifies conflict, but on the other geographic proximity leads to economic trade which according to neoliberalists diminishes conflict.

The point of this paper is to rectify this paradox by examining how trade and geographic distance work together to influence international interactions. We do so by showing that trade mitigates the increased conflict brought about by geographic proximity (as well as mitigates the effects of distance in diminishing cooperation). As we hope to illustrate, our findings are important both to the geography and conflict as well as to the trade and conflict literatures because we show how geography and trade work together in influencing international interactions. Further Mansfield and Pollins (2001:840-841) argue "too little effort has been made 
to assess whether the interdependence-conflict relationship is bounded by space...” This paper explicitly deals with how geographic space affects the conflict-trade relationship.

\section{Background}

There exists substantial evidence that closer countries are more likely to engage in conflictive behavior. According to Vasquez the opportunity for conflict of interest type disagreements between two countries increases with the number of interactions. Since “contiguity is the single largest factor promoting interactions, contiguous states are more likely to have serious disputes and war.” [Vasquez, 1995, p. 280] In addition, not only are contiguous countries more likely to have initial disputes, such disputes between neighboring countries are more likely to evolve into enduring rivalries (Stinnett and Diehl, 2001). The resolution of an initial conflict may not end the rivalry between countries, allowing other issues to escalate into disputes. On the other hand, contiguous nations face low transportation costs leading to enhanced economic trade (Gowa, 1994). Similarly, empirical estimation of gravity models finds that the distance between countries is inversely related to international trade (Leamer and Levinsohn, 1995; Egger, 2002).

Theoretical neoliberal models (Polachek 1980) examine how trade influences conflict using an expected utility model. Polachek, Robst, and Chang (1999) extend the model to include an indirect effect of distance on conflict. In their paper, distance reduces trade due to increased transportation costs, with the reduction in trade leading to an increase in conflict. However, their model ignores the direct effect that distance has on conflict. Others consider situations where trade may be more or less important to international conflict. For example, Dorussen (1999, 2002) develops a multi-country model to show that trade is most important when there are few 
barriers to trade, when countries will not trade post-conflict, and when there are more countries in the system. Hegre (2004) uses an expected utility framework to show that trade has a stronger effect when there is a symmetrical dependence on trade. Morrow (1999) presents a game theoretic model that examines how trade influences the relative resolve of both initiators and targets of disputes. Trade reduces the initiator's willingness to fight, but also reduces the target's willingness to fight. The reduction in the target's willingness to fight increases the incentives for the actor to initiate conflict and bargain for concessions from the target. As such, trade has an indeterminate effect on conflict. Similarly, Gartzke, Li, and Boehmer (2001) also discuss how trade (or threatening to restrict trade) may be used as a signal of resolve without resorting to violent conflict. As such, trade may reduce violent military conflict but actually increase nonmilitary conflict, particularly if one country is more hesitant to fight.

The relationship between trade and conflict has received substantial empirical investigation as well. While there is little disagreement that closer countries fight more, the question of whether trade reduces conflict is debated in the literature. ${ }^{1}$ On one side, Barbieri $(1996,2002)$ argues that bilateral trade increases dyadic conflict. On the other side, numerous studies have found that trade reduces dyadic conflict (Polachek, 1980; Oneal, et al. 1996; Oneal and Ray, 1997; Oneal and Russett, 1997, 1999a, 1999b). Several studies have attempted to reconcile the disparate findings in the literature (Gartzke and $\mathrm{Li}, 2003 \mathrm{~b}$ ), but the debate continues (see Gartzke and Li, 2003c; Oneal, 2003; Barbieri and Peters, 2003). Much of the debate centers on measurement issues, particularly how to measure economic linkages. Such economic links and interdependences are complex and difficult to quantify with different measures used in the literature. Gartzke and Li (2003b) show that the use of different measures of economic interdependence can account for the contradictory findings in the literature. 
While the importance of developing meaningful measures of economic interdependence is clear, this paper does not seek to contribute to this discussion. The point of the paper is not to consider whether trade in general is important to international conflict, rather this paper attempts to disentangle the contradictory incentives that trade and geographic proximity provide for countries to engage in conflict. We argue that while proximity provides incentives for conflict, trade mitigates these incentives. As such, trade and geographic proximity interact to determine the level of international conflict (and cooperation).

There are at least two potential ways to examine the interactive role of trade and distance in determining international interactions. First, geographic distance has a dual role as it influences conflict directly through reasons discussed by Vasquez and others, and second geographical distance also affects conflict indirectly by influencing trade. As such, one could examine how distance affects trade, which then affects conflict. As geographic distance falls, trade increases, which is expected to reduce conflict. Chang, Polachek, and Robst (2004) use this approach to show that conflict between closer dyads would be even greater if not for the economic gains due to trade. That paper attempts to address the potential endogeneity of trade by estimating a simultaneous equations system modeling trade and conflict. The selection of instruments, however, was not based on a theoretical relationship nor is it clear the instruments meet necessary econometric criteria.

While we revisit the issue of simultaneity later in the paper, the primary purpose of the paper is to consider an alternative perspective by examining whether trade affects conflict differently depending on distance. This finding has implications with regard to the trade-conflict literature in general. There is now research on how the effects of trade vary depending on the particular commodities traded. Whereas Polachek (1980) concentrated on strategic commodities 
such as oil, Reuveny and Li (2004) examine a larger number of different commodities. This

paper shows that the effects are not uniform in another way, namely by geographic distance. This implies that the "Kantian Tripod" is more complicated than a simple triangulation because the way one triangulates varies with distance. In other words, instead of focusing on the main effects of trade or geographic distance as in prior research, one can look at the interactive effects of trade and distance on conflict. In particular, we focus on the questions of whether the effect of trade depends on the distance between countries, and whether the effect of geographic proximity on conflict depends on the level of trade.

\section{Hypotheses}

A world system encompasses numerous countries, many trading with each other because the virtues of trade make each country better off economically. What results is a system of intercountry interdependence, which if based on free market principles including free trade and the full mobility of resources, would result in maximal global output. Any country breaking off such a trade relation would decrease its own long-run economic well-being as well as perhaps the well-being of its trading partners and other countries. Nations, however, often do not operate to maximize global output and instead may act to maximize their own welfare. For example, trade may be used as a strategic tool to signal other countries about intentions. In general, much research has examined trade in the context of game theory, with trade creating harmony between countries or a prisoners' dilemma in which countries interact with a risk of cheating.

At the same time the geographic distance between countries affects the optimal amount of interaction between countries. We define interactions to include both cooperative and conflictive events. As such, incentives for interaction may increase conflict, or cooperation, or 
both. Neighboring countries have more opportunities and incentives for interaction, both conflictive and cooperative. Some of the incentives for conflict were discussed in Vasquez (1995) and were mentioned earlier in this paper. Incentives for cooperation also exist for neighboring countries. For example, Seigle (1988) and Schiff and Winters (1997) discuss how nearby countries may cooperate in order to increase regional security.

Polachek (1980) and Polachek, Robst, and Chang (1999) present an analytical model based on expected utility theory to examine the optimal level of conflict. In this paper we present a diagrammatic representation of the model in Figures 1 and 2. The expected utility model is based on countries behaving in a way to maximize utility subject to constraints. While the discussion in this paper is based on conflict (and cooperation) being determined by equating the marginal gains and marginal costs of conflict (and cooperation), we also incorporate some of the theoretical advances in recent research.

One can apply Figure 1 to show how distance and trade affect conflict. Trade increases the marginal cost of conflict from MC to MC*. The marginal cost rises because conflict reduces the gains from trade either through a direct reduction in trade or indirectly through tariffs or quotas. The increase in the marginal cost depends on whether trade resumes post-conflict (assuming the target remains in existence). If trade resumes post-conflict the long-term cost is less than if trade does not resume (Dorussen, 1999). Trade often does resume post-conflict (Barbieri and Levy, 1999), but there are still significant short-run disruptions in trade (Anderton and Carter, 2001). In addition, a potential actor is unlikely to know with certainty whether the target will resume trade post-conflict. A greater commitment by the target not to resume trade, the greater the actor's perceived marginal cost to conflict (Dorussen, 2002).

The slope of the marginal cost curve is steeper for more distant dyads. This is both 
because finding an alternative source of trade gets more expensive with distance and because moving a given piece of military equipment a greater distance is more costly. For these reasons the cost for relatively mild forms of conflict such as recalling an ambassador may not differ substantially between close and distant dyads, but certainly these differences rise when large amounts of trade are lost or great amounts of military equipment are be used. Thus severe conflict is much more costly when the countries are far apart. These marginal cost curves are designated with a prime (MC’ and $\mathrm{MC}^{\prime *}$ ) when referring to an actor dealing with a distant target, and are designated by an asterisk (MC and $\mathrm{MC} *$ ) when referring to an actor dealing with a close target. Given the marginal gain curve (MG), trade lowers the optimal level of conflict for both nearby and distant dyads.

$<$ Figure 1 $>$

Before discussing some of the hypotheses, the concept of trade from this theoretical perspective merits further discussion. Trade and its impact on conflict are very complex and a function of many different factors. First, expected utility models often assume that trade is determined exogenously. Clearly, the level of prior conflict between countries affects the amount of existing trade. As such, the model is a static model that examines decisions in time $t$ given past economic and political conditions, but could be expanded to incorporate the endogeneity of trade. Second, as Copeland (1996) discusses, observed trade is less important to the decision process than expected trade. In this case, countries must make decisions incorporating expectations about future economic and political relationships. Expectations about the future are likely to be a function of past behavior and signals about future behavior. Third, existing trade and expectations about future trade are likely to be a function of signals from trading partners. Trading partners may forgo gains from trade in order to signal their resolve in a 
potential or actual dispute. Potential targets with greater resolve can impose greater costs to conflict on actors or may reduce current trade in an effort to signal its resolve and discourage potential conflict by the actor (Gartzke and Li, 2003a). Overall, trade is a complex decision variable much like conflict itself. Distance, while an important factor in determining international conflict and cooperation, is not a choice variable; it is a given exogenous factor.

In spite of these issues, Figure 1 leads to two testable hypotheses.

Hypothesis \#1: Trade leads to a greater reduction in conflict for closer dyads than more distant dyads.

Given Figure 1, optimal conflict falls from point D to C for closer dyads and from point B to A for more distant dyads. But as one referee indicated, if the MC curve shifted up in a parallel way "we would still see that trade diminishes conflict, though the effect of greater trade would be the same for dyads near and far."

The depiction of the MC curves in Figure 1 is consistent with the current literature. For example, the same hypothesis can be derived from Dorussen $(1999,2002)$ and Hegre (2002) who take a completely different approach. They model conflict as a function of the ratios of the probabilities of victory with $p_{\lambda}$ denoting the minimum required probability of victory with trade while $p_{0}$ the minimum required probability without trade:

$$
\frac{p_{\lambda}}{p_{o}}=1+\lambda(n-1) z
$$

where

$$
z=\frac{r^{2}\left(1-p_{s}\right)(1-\phi)}{r(r-1)\left(1-p_{s}\right)(1-\phi)+c}
$$


Thus, the probability ratio is a function of gains from trade with trade restrictions $(\lambda)$, the number of countries in the system $(n)$, resources $(r)$, the probability of a stalemate $\left(p_{s}\right)$, a discount factor that reflects the rate of time preference $(\Phi)$, and the cost of conflict (c). Dorussen (2002) and Hegre (2002) take the derivative of the ratio with respect to $n$, the number of countries in the system, to show the pacifying effect of trade is greater when there are more states. ${ }^{2}$ In other words, as the number of countries in the system increases, the minimum required probability of victory increases more when there is trade than when there is no trade for the actor to initiate conflict. In terms of our paper, we take the derivative with respect to $c$, the cost of conflict. Taking the partial derivative of the ratio with respect to cost leads to the prediction that the pacifying effect of trade is greater when the cost of conflict is lower:

$$
\partial\left(\frac{P^{\lambda}}{P^{0}}\right) / \partial c=-\frac{\lambda(n-1)\left[r\left(1-p_{s}\right)(1-\phi)\right.}{\left[r(r-1)\left(1-p_{s}\right)(1-\phi)+c\right]^{2}}<0
$$

If the cost of conflict is lower for closer countries, trade has a greater pacifying effect. Thus, our use of the expected utility model is not the only model that could be used to derive the hypotheses tested in this paper.

Hypothesis \#2: Geographic proximity leads to a greater increase in conflict for dyads with little or no trade.

Optimal conflict increases from point A to C for trading dyads and from point B to D for nontrading dyads. Geographic proximity increases the incentives for conflict regardless of whether countries trade. Conflict increases more for non-trading dyads both because the marginal cost curves are horn-shaped and because we expect the marginal gain from conflict to diminish less quickly when the target of the conflict is closer. 
There are several extensions that could be incorporated into the presentation. The marginal gain to conflict may be lower for distant dyads due to the smaller potential for security or land gains through conflict. ${ }^{3}$ Control over resources is more difficult to obtain and retain when there is a greater distance between countries (Anderton, Anderton, and Carter, 1999). In addition, trade is assumed to increase the MC of conflict, but such an increase may differ based on distance. For example, the composition of trade differs for nearby and distant countries. Hanson and Xiang (2004) present evidence that closer countries tend to trade goods that have higher transportation costs and fewer substitutes. As such, for a given level of trade, the gains from trade may be greater for nearby countries, implying a greater cost to a disruption in trade

Another extension would consider whether the marginal gain from conflict differs across trading dyads. One reason for trade to exist is that one country has a resource or commodity that the other country desires. As such, the ability to gain control over the desired resource may be viewed as a potential benefit to conflict, but only if the actor would actually be successful in such an attempt. If the actor was unsuccessful, then access to the desired resource through trade might also be lost. If the actor perceived a high likelihood of gaining control over the resource and the resource was sufficiently valued, the MG to conflict could increase to the point that optimal conflict would increase. There is another reason to expect higher marginal gains to conflict for some actors. The MG to non-military conflict among trading partners may also be greater if a target faces a particularly high cost to conflict. As such, an actor may have an incentive to initiate a degree of conflict in order to negotiate a greater share of the gains from trade. While we do not explicitly include this extension in figure 1 , we will revisit the issue in the empirical section of the paper.

Figure 2 considers the distance-trade-cooperation relationship. In this case, curve MC 
depicts the marginal cost of cooperation while MG is the marginal gain from cooperation. The optimal level of cooperation is determined by the intersection of the two curves (point A). As the distance between countries decreases, there are greater benefits to cooperative behavior. One possible reason for this is the security that can be acquired through cooperation with neighboring countries (Seiglie, 1988; Schiff and Winters, 1997). A country gains greater security through cooperating with a nearby country, increasing the benefits to cooperative behavior. For example, Sandler (1999) argues that one reason for the formation of alliances is the mutual security that arises when interior borders require less protection. This implies a shift in the MG curve to $\mathrm{MG}^{\prime}$ and an increase in optimal cooperation to point C.

We assume that trade also affects the marginal gain to cooperation. Countries that trade often cooperate in other ways, for example by forming military alliances. In other words, the presence of trade and the mutual benefits of trade can strengthen other forms of cooperative behavior such as alliances. An ally that would potentially lose gains from trade would be expected to provide stauncher support for a country facing conflictive behavior from a third party. Thus, trading partners have a greater marginal gain from cooperation regardless of geographic distance. Graphically this is depicted by $\mathrm{MG}^{*}$ and $\mathrm{MG}^{\prime *}$. Introducing trade for geographically close countries increases optimal cooperation from point $\mathrm{C}$ to $\mathrm{D}$, while trade increases optimal cooperation among distant countries from point A to B.

$<$ Figure 2>

This leads to two additional testable hypotheses.

Hypothesis \#3: Trade leads to a larger increase in cooperation for distant dyads than close dyads.

Optimal cooperation increases from point C to D for close dyads and from point A to B for 
distant dyads. This may seem counterintuitive, but suggests that closer dyads already have an incentive to cooperate. Introducing trade increases the incentive to cooperate, but trade has a larger marginal effect when the countries are more distant and have little incentive to cooperate based on proximity.

Hypothesis \#4: Geographic proximity leads to a greater increase in cooperation for dyads with little or no trade.

Optimal cooperation falls from point D to B for trading dyads and from point C to A for nontrading dyads. Countries that trade have an incentive to cooperate. Proximity has a larger effect on cooperative behavior when the incentives to cooperate derived from trade are absent.

Similar to the hypotheses regarding conflict, the hypotheses regarding cooperation could also be derived using alternative models. For example, Snidal (1991) develops a model that examines determinants of international cooperation. A country has a choice in each period. It can receive gains from cooperation for multiple periods which must be discounted to determine the present value of benefits, or alternatively, the country can renege, extract gains for a single period, and cease cooperating. The decision is determined by the discount rate used to compute the present value of cooperation. The higher the discount rate, the lower the future value, and the more likely the country will renege. The discount factor required to support cooperation is related to gains from trade and country proximity in a nonlinear way. Appropriately differentiating the function illustrates that the cooperation-enhancing effects of trade are mitigated by geographic proximity.

To summarize, trade increases cooperation and decreases conflict. Proximity increases conflict and increases cooperation. Trade mitigates the increased conflict and cooperation brought about by proximity. The effects of this mitigation lessons as distance rises. A given level 
of trade from a close country need not result in the same reduction of conflict as trade from a distant country because trade need not shift the marginal gain of conflict and cooperation equally. In short, the conflict-trade model has two parts: First is the marginal cost of conflict, and second is the direct utility associated with conflict. The direct utility associated with conflict is not independent of distance. By the same token, a given level of trade need not have the same effect in increasing cooperation as it does in decreasing conflict. Here increases in the marginal cost of conflict brought on by a given level of trade need not equal the increased marginal gains.

As a simple example, our model implies trade to have a larger effect increasing cooperation than decreasing conflict for more distant countries. A great deal of research indicates that distant countries have less incentive (and ability) to interact; either through conflict or cooperation. If we assume that prior research is correct on this topic, then we argue introducing trade provides little incentive for distant countries to decrease conflict further since conflict is already small. On the other hand, trade provides a positive incentive for cooperation when there was little incentive previously. The substantial growth in trade between the US and China would provide considerable incentive for cooperation between the countries. The only way we can see trade substantially reducing the incentives for conflict is if we call into question the idea that distant countries fight less; but we see little reason to question this relationship.

\section{Data and Methodology}

Following Reuveny (2003:255) who argues "it would be beneficial for the field of international relations to go back and routinely use events data” our primary source of data on conflict and cooperation between dyads is the World Event Interaction Survey (WEIS). WEIS is an extensive, longitudinal collection of cooperative and conflictive events derived from the New 
York Times (McClelland, 1976; updated through 1992 by Tomlinson at the U.S. Naval Academy). These events are coded into 61 categories representing different kinds of cooperation and conflict. Events are weighted based on severity according to a scale developed by Goldstein (1992). We concentrate on an annual measure of conflict and cooperation for each dyad with data pooled for the years 1966-1992. WEIS is distinct from the often used COW and MIDs data sets in at least two ways. First, it contains information on both cooperative and conflictive events. Second, it contains data on both severe and mild forms of conflict and cooperation.

The two primary explanatory variables are (lagged) trade and distance. Barbieri (1998) compiled trade data on a dyad basis. Most of the data are from the International Monetary Fund's Direction of Trade Statistics, but have been supplemented with data from numerous other sources. Barbieri (1998) does not include dyads in the data or her analyses when trade is equal to missing since it is unclear whether this indicates no trade or missing trade figures. Oneal and Russett (1999a) code missing trade data as zero trade between countries. We consider this to be reasonable for this time frame and code missing data as zero trade, but recognize that it may introduce some degree of measurement error. As such, we also eliminated dyads with missing trade data to determine the sensitivity of our results to this decision. The results are very similar and are not reported to conserve space. The specification includes dyadic trade, in 1984 dollars, in the prior year to reduce potential endogeneity.

The use of dollar trade to measure the economic gains from trade may be questioned. Studies typically use the trade-to-GDP ratio or the proportion of bilateral trade to a state's total trade. None of the typical measures of trade measure the gains from trade that economists would argue are relevant to international interactions (Polachek and McDonald, 1992). In addition, the coefficients using a ratio measure of interdependence are difficult to interpret. One does not 
know if the numerator or the denominator drives the effects. The gains from trade are better approximated by incorporating not just a level or ratio of trade, but also the elasticity of demand for the goods of another country. Countries may have a high level of trade, but have many potential trading partners and hence a high elasticity of demand. On the other hand, a small elasticity of demand would imply few alternatives and greater economic interdependence. The most popular measures of "economic interdependence" used in the literature do not measure such interdependence. But the problem is that bilateral elasticity measures are not available. As such, given our desires to avoid the debate over using the trade-to-GDP ratio versus the trade share measure and confounding the effect of the numerator and denominator, we use total trade between countries but acknowledge there could be shortcomings even with this approach. The other primary analysis variable, distance, is the distance in miles between the capitals of the actor and target. Of course, proximity can also be measured by whether two countries are contiguous, which is typically defined as land contiguity or separation by less than 150 miles of water. Indeed, much of the discussion in the literature surrounding proximity involves issues related to contiguity. We focus on distance since the distance between noncontiguous countries can vary significantly. Distance is also typically used as a proxy for transportation costs in gravity models (e.g., Leamer and Levinsohn, 1995; Egger, 2002; Hanson and Xiang, 2004). As such, we may expect transportation costs and resulting trade to be more interrelated with distance in determining conflict than contiguity.

Before looking at the standardizing variables and regression specification, we present an example of our hypotheses using WEIS data where the United States is the actor country. The example focuses on countries with which the US has political and economic interactions. First, let's look at two countries close to the US. During the 1980s, the US and Cuba had no official 
trade and considerable conflict (avg. weighted conflict of 34.8 per year). The US and Mexico had considerable trade (\$27.4 billion) and much less conflict (10.7) during the 1980s. Looking at countries distant from the US, the Philippines represent an example of a country with which the US had relatively low trade (\$4.1) and high conflict (18.2), while the US and South Korea had high trade (17.0) and low conflict (7.4). In this example, conflict falls as trade increases for both the close and distant dyad, while conflict also falls as distance increases for both high and low trade dyads. The increase in trade has a much larger impact on conflict for the closer dyads (34.8 to 10.7) than the distant dyads (18.2 to 7.4). Similarly distance has a larger effect among non-trading partners (34.8 to 18.2) than trading partners (10.7 to 7.4 ). This example is consistent with the two hypotheses presented above addressing the interactive effect of trade and distance on conflict.

Examples are interesting but certainly do not prove a hypothesis. Many factors vary across dyads that influence the degree of conflict. Standardizing variables are included to hold constant other factors that may affect both trade and conflict. The data are derived from the Expected Utility Generation and Data Management Program (EUGene) (Bennett and Stam, 2000). Such variables include categorical variables denoting whether the countries are allies (ally1=1 if defense pact; ally2=1 if neutrality; ally3=1 if entente), whether one or both of the countries are major powers (maj $1=1$ if actor and target are major powers; maj2=1 if actor is only major power; maj3=1 if target is only major power), and continuous variables denoting DEMHI, the higher democracy score in the dyad, DEMLO the lower democracy score in the dyad, the ratio of national capabilities indexes (actor divided by target), and lagged conflict (or cooperation). Major powers in the Correlates of War data are China, France, United Kingdom, United States, and USSR. Democracy scores are computed for the actor and target as the 
difference between the values of democracy ( 0 to 10$)$ and autocracy ( 0 to -10$)$ from the Polity III data. Oneal and Ray (1997) argue that the two democracy scores, DEMHI and DEMLO, better capture the political distance between countries than a single additive or multiplicative democracy score. All standardizing variables are also lagged to reduce potential endogeneity. We use ordinary least squares (OLS) multivariate regressions to test the propositions. We examine how distance and trade are related to dyadic conflict and cooperation. Separate regressions are estimated with the dependent variable equaling weighted conflict and weighted cooperation. One problem with events data is that certain countries are more newsworthy than others. If newspapers concentrate on certain countries, these countries will have more conflict and cooperation in our data. Indeed, preliminary analysis found that the WEIS data has severe problems with selection issues. Much reported conflict and cooperation is between relatively few dyads. We explore two approaches to account for the tendency to report data more frequently on specific states. First, a lagged dependent variable is added to the specification to account for the temporal correlation in the dependent variable (Beck, Katz and Tucker, 1998; Beck and Katz, 2001). The use of a lagged dependent variable is appropriate when the dependent variable is continuous. We explored using multiple lags (up to five years), but found this had little effect on the results and we report results using the single lag.

Sensitivity analysis found the inclusion of a lagged dependent variable was not adequate to account for the substantial reporting on the interaction between two dyads (US-Canada and US-Japan). These two dyads appear to be outliers and the results are very sensitive to how we account for these dyads. Since it is inappropriate to allow a few observations to alter general results, we also included categorical variables in the specification denoting these two dyads. Given that distance is time invariant, these dyads will not contribute to the estimated distance- 
conflict relationship, but since trade varies over time they will contribute to the estimated tradeconflict relationship. Results were relatively insensitive to including variables denoting other closely followed dyads. The specifications take the form:

$$
\begin{aligned}
& \text { Conflict }_{i j t}=\alpha_{0}+\alpha_{1} \text { Trade }_{i j t-1}+\alpha_{2} \text { Distance }_{i j t-1}+\alpha_{3} T_{i j t-1} \cdot D_{i j t-1}+\alpha_{4} \text { Conflict }_{i j t-1}+\alpha_{5} \text { Dyad }_{k}+\alpha_{6} X_{i j t-1}+\varepsilon_{i j t}(1) \\
& \text { Coop }_{i j t}=\alpha_{0}+\alpha_{1} \text { Trade }_{i j t-1}+\alpha_{2} \text { Distance }_{i j t-1}+\alpha_{3} T_{i j t-1} \cdot D_{i j t-1}+\alpha_{4} \text { Coop }_{i j t-1}+\alpha_{5} \text { Dyad }_{k}+\alpha_{6} X_{i j t-1}+\varepsilon_{i j t}(2)
\end{aligned}
$$

where Conflict $t_{j i t}=$ weighted frequency of conflict by country $i$ towards country $j$; Coop $_{i j t}=$ weighted frequency of cooperation by country $i$ towards country $j$; Trade $_{i j t-1}=$ total trade (in billions US\$) between countries $i$ and $j$ in time $t-1$; Distance $_{i j t-1}=$ distance (in thousands of miles) between the capitals of country $i$ and country $j$; $T_{i j t-1} \cdot D_{i j t-1}$ represents to interaction between trade and distance; Conflict $t_{j t-1}$ is dyadic conflict in the prior year; Dyad $_{k}$ denotes two categorical variables for the US-Japan and US-Canada dyads; $X_{i j t-1}=$ a vector of standardizing attributes; and $\varepsilon_{i j}=$ a random error term normally distributed with mean zero. All observations are weighted to account for potential heteroskedastic error structures.

Second, a fixed effects approach is used to account for unobserved time-invariant characteristics that may influence conflict and cooperation. The unobserved characteristic we want to control for is the propensity for certain countries to receive more press coverage, and as a result, have more reported conflict and cooperation in events-type data.

The use of fixed effects models is controversial in international relations research. Green, Kim, and Yoon (2001) use dyad fixed effects to assess the effect of economic interdependence on conflict. Their study was strongly criticized in comments by Beck and Katz (2001) and Oneal and Russett (2001). In essence the comments argue that including variables denoting each dyad is inappropriate in this type of analysis, especially given the rare nature of the dependent variable. We agree that a dyad fixed effects approach would be inappropriate for 
most dyads in our analysis. First, the extremely large number of dyads and relatively short time frame results in unstable coefficient estimates. Second, the distance between countries is a time invariant characteristic and a dyad-level fixed effects model would be unable to disentangle the distance effect from the time invariant fixed effect. Beck and Katz also note that a dyad fixed effects model is essentially the same as adding a lagged dependent variable to the specification with a coefficient restricted to one.

In order to avoid these criticisms we included categorical variables in the fixed effects specification denoting each actor in the data. Such an approach allows for variation in distance between the actor and various targets, avoiding the main pitfall of a dyad fixed effects approach. Once again, the results were sensitive to the treatment of the US-Canada and US-Japan dyads and we include categorical variables denoting these two dyads. Thus, the fixed effects specification examines the effect of trade and distance on dyadic conflict/cooperation holding constant the average propensity of an actor to engage in conflict or cooperation (or the average propensity of newspapers to report on such interactions). In this case, the specifications are:

$$
\begin{aligned}
& \text { Conflict }_{i j t}=\alpha_{0}+\alpha_{1} \text { Trade }_{i j t-1}+\alpha_{2} \text { Distance }_{i j t-1}+\alpha_{3} T_{i j t-1} \cdot D_{i j t-1}+\alpha_{4} \text { Actor }_{i}+\alpha_{5} \text { Dyad }_{k}+\alpha_{6} X_{i j t-1}+\varepsilon_{i j t}(3) \\
& \text { Coop }_{i j t}=\alpha_{0}+\alpha_{1} \text { Trade }_{i j t-1}+\alpha_{2} \text { Distance }_{i j t-1}+\alpha_{3} T_{i j t-1} \cdot D_{i j t-1}+\alpha_{4} \text { Actor }_{i}+\alpha_{5} \text { Dyad }_{k}+\alpha_{6} X_{i j t-1}+\varepsilon_{i j t}(4)
\end{aligned}
$$

where Actor $_{i}$ is a vector of categorical variables denoting each actor. Both approaches are estimated to determine whether the results are sensitive to the specification.

\section{Results}

Descriptive statistics

Descriptive statistics are provided in Table 1. Average dyadic conflict and cooperation are similar at .213 and .207 respectively. The average distance between countries is nearly five 
thousand miles, while average trade is 165 million (1984 US dollars). The higher democracy score is more than twice as great as the low democracy score. Nearly five percent of dyads in the data have a defense pact, while another six percent are defined as ententes. Over seven percent of dyad year observations involve at least one major power.

Table 2 contains the distribution of annual weighted conflict and cooperation. The vast majority of dyad-year observations have neither conflictive nor cooperative events in the data. This may reflect the lack of interaction between distant, particularly small, countries or the lack of coverage of many countries in the New York Times. Of those dyads with conflict or cooperation, most appears to be relatively mild in nature. Of those with substantial conflict or cooperation, it is unclear whether this represents the magnitude of conflict/cooperation or the frequency.

We explored this issue in more detail by examining the individual WEIS observations. Of the nearly fifty-thousand events involving conflict, 297 involve military attack, while another 814 entail seizing possessions. Twenty percent of the events involve nonmilitary destruction or injury, the third most serious conflict category. Another twenty-percent of conflictive events involve blaming or disapproving, which ranks $24^{\text {th }}$ in severity out the 33 conflict categories. Overall, the conflictive events in the WEIS data include a wide variety of actions that range widely in severity. Of the dyad-year observations with the most conflict, some are heavily weighted by military conflict (e.g., the US and Vietnam) while others represent the frequency of events (e.g., US and USSR).

A similar situation exists for cooperative events. Of the forty-five thousand cooperative events, 790 involve military assistance and 691 entail economic aid. The most prevalent cooperative event, accounting for nearly twenty-five percent of the observations, is to meet with 
representatives of another country. This is a relatively weak form of cooperation ranking $24^{\text {th }}$ out of the 27 cooperative events. Most of the cooperative events represent moderate events, including releasing prisoners or returning property, assuring or reassuring, or agreeing to future actions.

\section{Conflict}

We presented two hypotheses that pertain to international conflict. First, we conjectured that trade leads to a reduction on conflict, with the marginal effect being greater for closer dyads than distant dyads. Second, we argued that distance leads to less conflict, with the effect being greater for dyads with little or no trade. The results in Table 3 are supportive of both hypotheses. $<$ Table 3>

Conflict falls as trade increases and as the distance between countries increases. The coefficient on the interaction between trade and distance is positive and significant, indicating that the negative effect on conflict from trade is mitigated when dyads are more distant. Of course, such a result can also be interpreted as showing that the negative effect on conflict from trade is enhanced when dyads are closer. Thus, trade has the greatest mitigating effect on conflict when countries have the greatest incentive to fight.

The positive coefficient on the distance-trade interaction also provides support for the second hypothesis. The coefficients on distance and the interaction indicate that a greater distance between countries leads to less conflict, but the marginal effect is smaller when countries trade. An alternative interpretation would be that closer countries fight more than distant countries, with the difference being greater among non-trading dyads.

Some of the other coefficients are worth discussion. As typically found in the literature, 
the greater DEMHI the greater the amount of conflict. However, contrary to prior research the greater DEMLO the greater the amount of conflict. Somewhat surprisingly, alliances (defense pact and ententes) appear to have greater conflict in the WEIS data. The capabilities ratio is inversely related to conflict and lagged conflict is strongly related to conflict. The strongly significant coefficient on lagged conflict suggests that a static model would be badly misspecified (Beck and Katz, 2001). The inclusion of actor fixed effects along with the lagged dependent variable adds little to the overall predictive power of the model. While the actor categorical variables are jointly significant, the R-square increases only .014 from .2562 to .2702. The results for DEMHI and DEMLO merit further discussion. The unexpected results for DEMLO are sensitive to specification and should be treated with caution. For example, not accounting for the substantial press following of the US-Japan and US-Canada dyads changes the sign for this coefficient. While we consider it inappropriate to allow two dyads to determine general relationships in research, such sensitivity might make further analysis of these variables worthwhile in future research. In general, variables such as DEMLO and DEMHI are reasonable when the direction of conflict cannot be ascertained. The WEIS data allow for identification of the actor and target. As such, we reestimated the model replacing DEMHI and DEMLO with variables denoting the actor's and target's democracy scores. The results show that the greater the actor's democracy score, the greater the amount of conflict, but the greater the target's democracy score, the lower the amount of conflict. In other words, actor democracies tend to be more conflictive with target non-democracies.

Earlier in the paper, we discussed how an actor’s desire to acquire resources from a potential target or influence the terms to trade might lead to increased conflict if the actor perceives a reasonable probability of success. We attempt to control for this probability by 
including variables in the specification measuring the capabilities ratio and whether one or both countries is a major power. It is noteworthy that conflict is lower when the actor has a capabilities advantage over the target, but is much higher when the actor is a major power and the target is not. While it is beyond the scope of this paper to adequately explore this issue, regressions were reestimated separately with the sample divided based on whether only the actor was a major power. Trade was found to have a weaker negative effect on conflict when only the actor was a major power. As such, the mitigating effect of trade on conflict might be weaker if a major power has a greater ability to appropriate desired resources.

\section{Cooperation}

There were two hypotheses presented pertaining to cooperation. First, trade leads to an increase in cooperation, with the effect being greater for distant dyads than close dyads. Second, distance leads to reduction in cooperation, especially for dyads with little trade. The results in Table 4 are consistent with both hypotheses.

\section{$<$ Table 4>}

The trade coefficient is negative and significant, indicating that trade would decrease international cooperation. But this is the case only when the distance between countries is extremely small. The positive and significant coefficient on the distance-trade interaction indicates that trade has a stronger effect on cooperation when the countries are more distant. While the marginal effects are discussed below, trade increases cooperation for almost all observed distances between countries. As trade increases, the incentives for cooperation increase. But an incentive to cooperate already existed for closer dyads, as such the marginal increase is greater for more distant dyads. 
Closer countries cooperate more than distant countries. The coefficient on the distance-trade interaction suggests that the effect of distance on cooperation is much smaller when countries trade. In other words, as the distance between countries increases the incentives to cooperate decline. But a dyad that trades still has an incentive to cooperate, thus the reduction in cooperation is smaller for trading partners.

\section{Marginal Effects}

The marginal effects of distance and trade are reported in Table 5. The marginal effects are computed by taking the derivative of the regression results with respect to trade (distance) and then evaluating the derivative across a range of distances (trade values). We only report the marginal effects from the most detailed specification that controls for lagged conflict/cooperation and actor fixed effects. Conflict decreases with trade, but not over the entire distribution of distance. Interestingly, trade increases conflict for dyads that are most distant. On the other hand, conflict falls as distance increases regardless of the amount of trade. $<$ Table 5>

Cooperation increases with trade, but the effect is much greater when countries are more distant. Cooperation falls when countries are farther apart, with trade having a relatively small impact on the relationship.

\section{Empirical Extensions}

Comments received from reviewers for this journal lead us to estimate several additional models. First, the inclusion of a single lagged dependent variable may not be adequate to account for temporal effects. We estimated actor fixed effects models with two, three, four, and 
five lags, but the coefficients on trade, distance, and the distance-trade interaction did not change significantly. The additional lagged dependent variables, while statistically significant, were taking explanatory power from the actor fixed effects. Another issue discussed by the referees involves the use of ordinary least squares (OLS) to estimate the regressions. The dependent variable is a weighted frequency of conflict or cooperation and might be considered a categorical or count variable instead of a continuous variable. As such, we estimated each specification using an ordered logit model. All results are qualitatively similar to those reported above. We do not report the logit results due to the difficulty in interpreting interaction coefficients in logit models (Ai and Norton, 2003). We did not explore using a count model given the dependent variables are weighted, and not merely counts.

A second problem with OLS centers on the simultaneous nature of conflict and trade. Conflict may be determined by trade, but trade is also determined by conflict. For example, Keshk, Pollins, and Reuveny (2004) used a simultaneous equations framework and found trade does not reduce conflict. We use lagged trade to mitigate this issue in the above section, but the existence of enduring rivalries suggests that this may not adequately account for the simultaneous nature of the relationship. Thus, we attempted to use a two-stage procedure to examine this issue. Several instruments were suggested by a referee including factor abundance and population, which are similar to the instruments used by Keshk, Pollins, and Reuveny (2004). We tested various combinations of actor and target population, iron and steel production, energy production, year, regions, and Tau with the system leader as instruments for trade. ${ }^{4}$ The results are presented in Table 6 and are consistent with those presented earlier in the paper. Trade reduces conflict, and the effect of trade is greatest when the distance between countries is smaller. 
$<$ Table 6>

Why do we find such different results from prior research? The answer lies in the selection of instruments. When using instruments similar to those used by Keshk, Pollins, and Reuveny (2004), we also were unable to find a significant relationship between trade and conflict. Below we discuss why these results may be biased due to the selection of invalid instruments.

There are at least two primary considerations in selecting instruments. First, the instruments must be correlated with the endogenous variable. The use of instruments weakly correlated with the endogenous variable can bias results as much as a model assuming exogeneity (Bound, Jaeger, and Baker, 1995). Staiger and Stock (1997) suggest a minimum F statistic of 10 for the joint significance of instruments in the first stage regression. The first stage regression passed this test for all combinations of instruments that we tested. Thus, the difference in results is unlikely to be explained by the correlation between the instruments and the endogenous variable.

The second requirement is that the instruments must be uncorrelated with the error. A system of equations using instrumental variables correlated with the error is typically referred to as overidentified. We use Bassman's (1960) test for overidentification, and our final choice of instruments was based on their ability to pass the overidentification test. In the end we were able to find a combination of instruments that passed the test for two of our three specifications, settling for the combination that produced the smallest $\mathrm{F}$ statistic in the one specification. But we began by testing combinations of instruments that included actor and target population since Keshk, Pollins, and Reuveny (2004) include actor and target population in their trade equation, but exclude the variables from their conflict equation. Overidentification tests lead us to reject 
the null hypothesis that actor and/or target population are valid instruments $(\mathrm{F}$ statistic $=436.4 ; \mathrm{p}$ value $<.0001) .{ }^{5}$ It is when we limit the analysis to valid instruments that we find a significant relationship between trade and conflict.

We recognize the importance of disentangling the simultaneous relationship between conflict and trade. The issue of simultaneity is complex and difficult to account for correctly. Instruments typically used in prior research fail exogeneity tests. The instruments we use pass the required statistical tests, but are not beyond criticism since their selection was not based on a clear conceptual framework. Clearly this issue requires further work in future research.

Lastly, one referee suggested we consider a different approach to looking at actor fixed effects. The coefficients on the actor categorical variables indicate how conflict varies across actors, but tell us little about why conflict varies across actors. Mundlak (1978) proposes including the mean of each independent variable instead of the fixed effect. As such, one can learn more about the differences between different actors along with looking at the effect of characteristics within actors. We estimated this type of specification with conflict and cooperation as dependent variables respectively and report the distance and trade coefficients in Table 7. The results for the within estimators are similar to the fixed effects specifications reported earlier. The between group estimates provide some interesting insights into average conflict across actors. For example, average trade may be indicative of the openness of a country. The average distance might indicate how isolated a country is. Actors that trade more are less conflictive. Thus, an actor that trades more is less conflictive overall, and in particular is less conflictive with trading partners. Surprisingly, actors that trade more tend to have less cooperation. Still, given the average level of cooperation by an actor, the actor tends to cooperate more with its trading partners. 
$<$ Table $7>$

Overall, the referee comments and additional analysis highlight important issues. The logit model and additional between group analyses are supportive of the results. Even the twostage analysis is supportive of the results. However, our difficulty in finding instruments that are sufficiently correlated with the endogenous variable and uncorrelated with the error amplify the serious econometric problems with instrument selection so as to cast serious doubt on the validity of many two-stage analyses of this topic already in the literature.

\section{Conclusion}

The distance between countries has clear implications for international conflict. While the effect of trade on conflict is questioned in the literature, much research shows the trading partners tend to have less conflict. Closer countries however, have more conflict and more trade. As such, Vasquez (1995) questions the ability of the “international interactions” hypothesis to explain the distance-conflict relationship. First, he asserts that empirical analysis does not uphold predictions that the distance-conflict relationship should be waning over time. Second, he asserts that the international interactions hypothesis contradicts the neoliberal approach. We argue that both the neoliberal economic interdependence and the international interactions approaches have a role in explaining the distance-conflict relationship. We present a diagrammatic model based on published theory and present empirical evidence to support our claim.

To summarize, both trade and distance are important determinants of international interactions. This paper shows that distance and trade have interactive as well as main effects on conflict. The main effects of distance may be due to a variety of reasons, including territorial 
disputes, the inability of small or developing countries to conflict with distant countries, and greater interactions between neighboring countries. The interactive effect suggests that the importance of economic interdependence depends on geography and that the importance of geographic proximity depends on economic interdependence. Both factors play important and interconnected roles in determining international interactions.

The results have a number of policy implications. Distance is a given that countries cannot not do much to alter (though in theory a country can move its capitol), while trade is a choice variable. As such, trade is a variable that countries can alter, with the effect of trade varying depending on the distance between countries. While trade may be used to affect many relationships between countries, we focus on international conflict and cooperation. Trade has a greater effect on conflict when countries are closer. As such, trade mitigates the incentives for conflict that exist between close countries. On the other hand, close countries already have an incentive to cooperate with each other. Trade has a greater effect on cooperation when countries are more distant and the incentives for cooperation that exist for close countries are not present.

Future research can look at many issues. For example, events data are a rich source of many types of international interactions. Research on the trade-conflict relationship focuses on aggregate measures of conflict, typically annual weighted conflict. Such an emphasis makes it difficult to disentangle the frequency of conflict from the severity of conflict. Dyads that interact often can look the same as dyads that have military clashes. Future research should look at the types of events to examine how trade influences the frequency and/or severity of conflict. As discussed earlier, research that examines the gains from trade would be especially useful. 


\section{References}

Ai, Chunrong and Edward Norton. 2003. "Interaction terms in Logit and Probit Models,” Economics Letters, 80(1), 123-129.

Anderton, Charles, Roxane Anderton, and John R. Carter. 1999. “Economic Activity on the Shadow of Conflict,” Economic Inquiry, 37(1), 166-179.

Anderton, Charles and John R. Carter. 2001. “The Impact of War on Trade: An Interrupted Time-Series Study,” Journal of Peace Research, 38(4), 445-457.

Barbieri, Katherine. 1996. “Economic Interdependence: A Path to Peace or a Source of Interstate Conflict?” Journal of Peace Research 33 (February): 29-50.

Barbieri, Katherine. 1998. International Trade Database (1870-1992). Version 1.1 (http://pss.la.psu.edu/TRD_DATA.htm).

Barbieri, Katherine. 2002. The Liberal Illusion: Does Trade Promote Peace? Ann Arbor, MI: University of Michigan Press.

Barbieri, Katherine and Karen Petersen. 2001. “Glory or Greed? Why States Fight Over Territory,” Paper Presented at the International Studies Association Annual Meetings, Chicago, February 2001.

Barbieri, Katherine and Jack S. Levy. 1999. "Sleeping with the Enemy: The Impact of War on Trade,” Journal of Peace Research, 36(4), 463-479.

Barbieri, Katherine and Richard A. Peters II. 2003. "Measure for Mis-Measure: A Response to Gartzke and Li,” Journal of Peace Research, 40(6), 713-719.

Basmann, Robert. (1960). On Finite Sample Distribution of Generalized Classical Linear Identifiability Test Statistics,” Econometrica, 45, 939-952.

Beck, Nathanial and Jonathan N. Katz. (2001) “Throwing Out the Baby with the Bath Water: A 
Comment on Green, Kim, and Yoon,” International Organization, 55(2), 487-495.

Beck, Nathanial, Jonathan Katz, and Richard Tucker. 1998. “Taking Time Seriously: TimeSeries-Cross -Section Analysis with a Binary Dependent Variable.” American Journal of Political Science, 42(4), 1260-1288.

Bennett, D. Scott, and Allan Stam. 2000. "EUGene: A Conceptual Manual.” International Interactions 26:179-204.

Bound, John, Jaeger, David A., and Regina M. Baker (1995) Problems with Instrumental Variables Estimation When the Correlation between the Instruments and the Endogenous Explanatory Variables is Weak. Journal of the American Statistical Association, 90, 44350.

Bueno de Mesquita, Bruce. 1975. "Measuring Systemic Polarity." Journal of Conflict Resolution. 19;187-216

Bueno de Mesquita, Bruce. 1981. The War Trap. New Haven: Yale University Press. Chang, Yuan Ching, Solomon Polachek, and John Robst. 2004. "Conflict and Trade: The Relationship Between Geographic Distance and International Interactions,” Journal of SocioEconomics, 33(4), 491-509.

Copeland, Dale. 1996. “Economic Interdependence and War: A Theory of Trade Expectations,” International Security, 20(4), 5-41.

Diehl, Paul. 1991. “Geography and War: A Review and Assessment of the Empirical Literature,” International Interactions, 17(1), 11-17.

Dorussen, Han. 1999. “Balance of Power Revisited: A Multi-Country Model of Trade and Conflict,” Journal of Peace Research, 36(4), 443-462. 
Dorussen, Han. 2002. “Trade and Conflict in Multi-Country Models: A Rejoinder,” Journal of Peace Research, 39(1), 115-118.

Egger, P. 2002. “An Econometric View on the Estimation of Gravity Models and the Calculation of Trade Potentials,” World Economy, 25(2), 297-312.

Gartzke, Erik and Quan Li. 2003a. “How Globalization Can Reduce International Conflict,” in G. Schneider, K. Barbieri, and N. Gleditsch, eds, Globalization and Armed Conflict, (New York: Rowman and Littlefield) pp 123-140.

Gartzke, Erik, and Quan Li. 2003b. “Measure for Measure: Concept Operationalization and the Trade Interdependence-Conflict Debate,” Journal of Peace Research, 40(5), 553-571.

Gartzke, Erik, and Quan Li. 2003c. “All’s Well That Ends Well: A Reply to Oneal, Barbieri, and Peters,” Journal of Peace Research, 40(6), 727-737.

Gartzke, Erik, Quan Li, and Charles Boehmer. 2001. “Investing in the Peace: Economic Interdependence and International Conflict,” International Organization, 55(2), 391-438.

Goldstein, Joshua S. 1992. "A Conflict-Cooperation Scale for International Events Data," Journal of Conflict Resolution, 36 (2): 369-85.

Gowa, Joanne. 1994. Allies, Adversaries, and International Trade. Princeton: Princeton University Press.

Green, Donald P., Soo Yeon Kim, and David H. Yoon. 2001. “Dirty Pool,” International Organization, 55(2), 441-468.

Hanson, Gordon H. and Chong Xiang. 2004. “The Home-Market Effect and Bilateral Trade Patterns,” American Economic Review, 94(4), 1108-1140.

Hegre, Håvard. 2004. “Size Asymmetry, Trade, and Militarized Conflict,” Journal of Conflict Resolution, 48(3), 403-429. 
Hegre, Håvard. 2002. “Trade Decreases Conflict More in Multi-Actor Systems: A Comment on Dorussen,” Journal of Peace Research, 39, 109-114.

Hirshleifer, Jack. 2000. “The Macrotechnology of Conflict,” Journal of Conflict Resolution, 44(6), 773-792.

Keshk, Omar, Brian Pollins, and Rafael Reuveny. 2004. “Trade Still Follows the Flag: The Primacy of Politics in a Simultaneous Model of Interdependence and Armed Conflict,” Journal of Politics, 66(4), 1155-1179.

Leamer, E.E., and J. Levinsohn. 1995. “International Trade Theory: The Evidence,” in Handbook

of International Economics, G. Grossman and K. Rogoff (eds.), Amsterdam: Elsevier, pp. 1339-1394.

McClelland, Charles. 1976. World Event/Interaction Survey Codebook. (ICPSR 5211). Ann Arbor, MI: ICPSR.

McMillan, Susan. 1997. “Interdependence and Conflict,” Mershon International Studies Review, 41(1), 33-58.

Mansfield, Edward and Brian Pollins. 2001. "The Study of Interdependence and Conflict: Recent Advances, Open Questions, and Directions for Future Research,” Journal of Conflict Resolution, 45(6), 834-859.

Mansfield, Edward and Brian Pollins. 2003. “Interdependence and International Conflict: A Conceptual and Empirical Overview,” in Edward Mansfield and Brian Pollins (eds.), New Perspectives on Economic Exchange and Armed Conflict. Ann Arbor, MI: University of Michigan Press (1-28).

Morrow, James. 1999. “How Could Trade Affect Conflict?” Journal of Peace Research, 36(4), 
481-489.

Mundlak, Yair. 1978. “On the Pooling of Time Series and Cross Section Data,” Econometrica, 46(1), 69-85.

Oneal, John. 2003. "Measuring Interdependence and Its Pacific benefits: A Reply to Gartzke and Li,” Journal of Peace Research, 40(6), 721-725.

Oneal, John, Frances Oneal, Zeev Maoz, and Bruce Russett. 1996. “The Liberal Peace: Interdependence, Democracy, and International Conflict, 1950-1985,” Journal of Peace Research, 33(1), 11-28.

Oneal, John and James Lee Ray. 1997. "New Tests of the Democratic Peace: Controlling for Economic Interdependence, 1950-1985” Political Research Quarterly, 50(4), 751-775.

Oneal, John, and Bruce Russett. 1997. “The Classical Liberals Were Right: Democracy, Interdependence, and Conflict, 1950-1985,” International Studies Quarterly, 41(2), 267293.

Oneal, John and Bruce Russett. 1999a. “Assessing the Liberal Peace with Alternative Specifications: Trade Still Reduces Conflict,” Journal of Peace Research, 36(4), 423442.

Oneal, John and Bruce Russett. 1999b. “The Kantian Peace: The Pacific benefits of Democracy, Interdependence, and International Organization, 1885-1992,” World Politics, 52 (October), 1-37.

Oneal, John and Bruce Russett. 2001. "Clean and Clear: The Fixed Effects of the Liberal Peace,” International Organization, 55(2), 469-486.

Polachek, Solomon. 1980. “Conflict and Trade,” Journal of Conflict Resolution, 24(1), 55-78.

Polachek, Solomon and Judith McDonald. 1992. "Strategic Trade and incentives for 
Cooperation,” in Manas Chatterji and Linda Forcey (eds.) Disarmament, Economic Conversion and the Management of Peace. New York: Praeger, pp. 273-284.

Polachek, Solomon, John Robst, and Yuan Ching Chang. 1999. "Liberalism and Interdependence: Extending the Trade-Conflict Model,” Journal of Peace Research, 36(4), 405-422.

Reuvany, Rafael. 2003. "Measuring Conflict and Cooperation: An Assessment,” in Edward Mansfield and Brian Pollins (eds.), New Perspectives on Economic Exchange and Armed Conflict. Ann Arbor, MI: University of Michigan Press (245-269).

Reuveny, Rafael and Quan Li. 2004. "Is All Trade the Same? The Effect of Disaggregated Bilateral Trade on Militarized Disputes,” paper presented at the Peace Science Society (International) Thirty-Eighth American Meeting, November 12-14, 2004, Houston, Texas.

Sandler, Todd. 1999. “Alliance Formation, Alliance Expansion, and the Core,” Journal of Conflict Resolution, 43(6), 727-747.

Schiff, Maurice and Alan L. Winters. 1997. "Regional Integration as Diplomacy,” CEPR Discussion Papers, 1690.

Schneider, Gerald, Katherine Barbieri, and Nils Peter Gleditsch, eds. 2003. Globalization and Armed Conflict. Lanham, MD: Rowman and Littlefield.

Seiglie, Carlos. 1988. "International Conflict and Military Expenditures: An Externality Approach,” Journal of Conflict Resolution, 32(1), 141-161.

Snidal, D. 1991, “Relative Gains and the Pattern of International Cooperation,” American Political Science Review, 85, 701-726.

Staiger, Douglas and James H. Stock. 1997. “Instrumental Variables Regression with Weak 
Instruments,” Econometrica, 65(3), 557-586.

Stinnett, Douglas M. and Paul F. Diehl. 2001. “The Path(s) to Rivalry: Behavioral and Structural Explanations of Rivalry Development,” Journal of Politics, 63(3), 717-740.

Vasquez, John. 1995. "Why Do Neighbors Fight? Proximity, Interaction, or Territoriality,” Journal of Peace Research, 32(3), 277-293. 


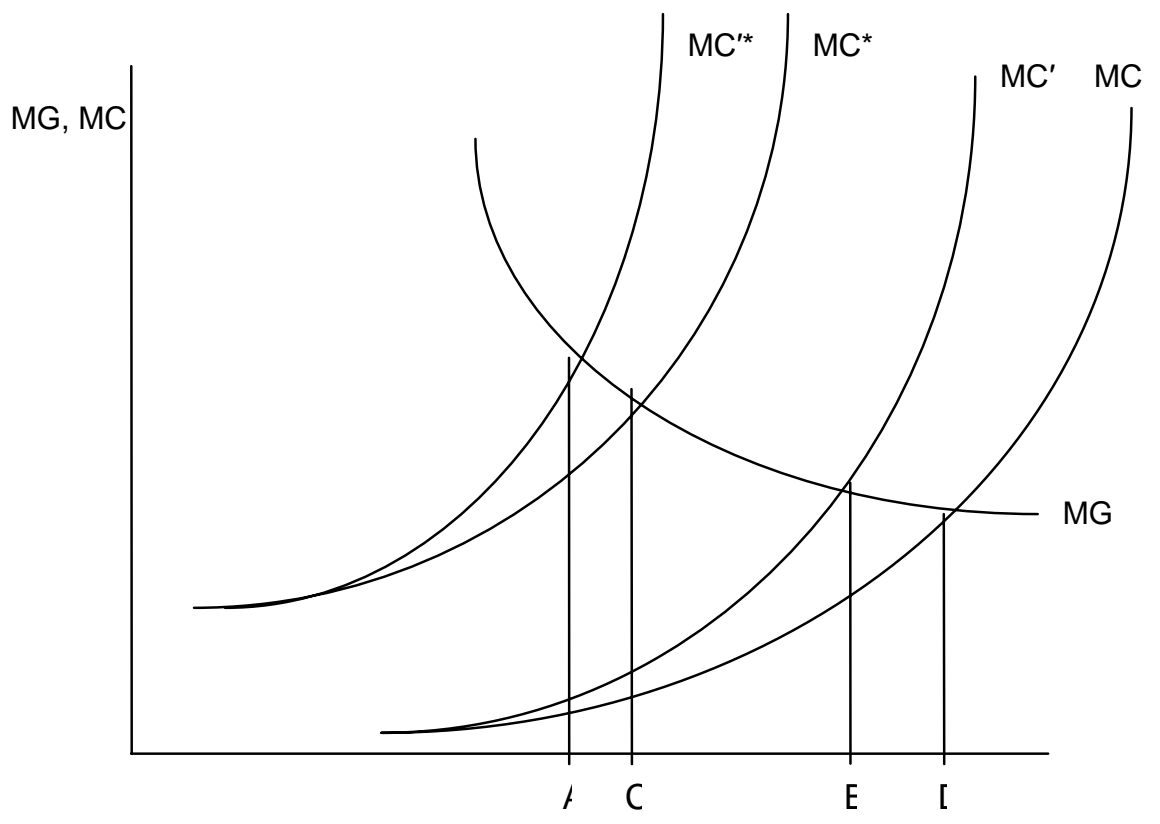

Figure 1

Optimal Conflict for Neighboring and Distant Dyads

Optimal conflict

Pt. A - Distant dyad, trade

Pt. B - Distant dyad, no trade

Pt. C - Close dyad, trade

Pt. D - Close dyad, no trade 


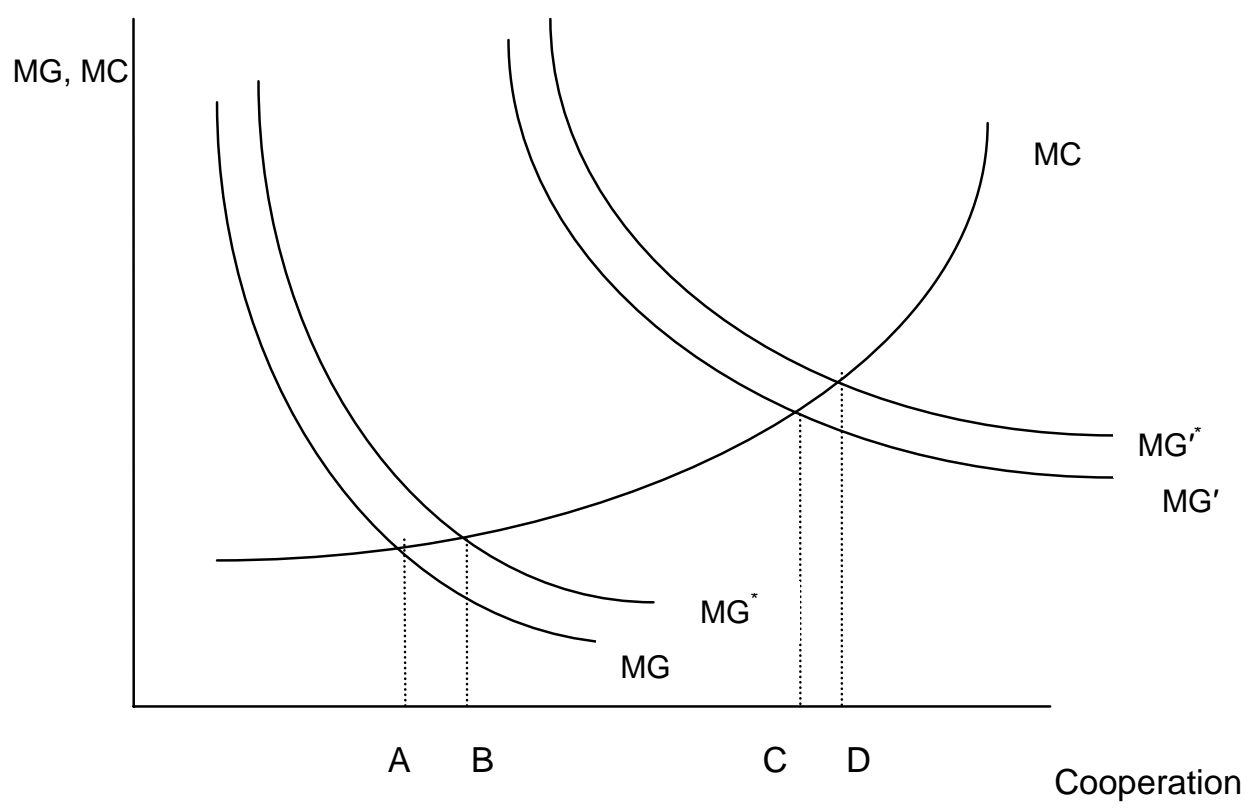

Figure 2

Optimal Cooperation for Neighboring and Distant Dyads

Optimal cooperation

Pt. A - Distant dyad, no trade

Pt. B - Distant dyad, trade

Pt. C - Close dyad, no trade

Pt. D - Close dyad, trade 


\section{Endnotes}

${ }^{1}$ For a thorough review of the literature, see McMillan (1997), Schneider, Barbieri, and Gleditsch (2003), and Mansfield and Pollins (2003).

2 See Durussen $(1999,2002)$ or Hegre (2002) for a complete description of the models.

3 Whereas distance reduces the marginal gain from conflict, Hirshleifer (2000) notes several cases where the gains to conflict may increase with distance. For example, conquered land and appropriated resources may be particularly valuable in strategic distant areas.

${ }^{4}$ Tau scores represent the rank correlation between two countries alliance portfolios (Bueno de Mesquita, 1975; 1981). We use the Tau with system leader where the alliance portfolio of the actor (or target) is correlated with the alliances of the system leader, which is Britain up to 1945, and the US from 1946 forward.

${ }^{5}$ While we didn’t test every variable, we might also hypothesize similar problems with using lagged trade and both actor and target population in the trade equation but not the dispute equation. 
Table 1

Variable Means

\begin{tabular}{|c|c|}
\hline Variable & Mean \\
\hline \multicolumn{2}{|l|}{ International Interactions } \\
\hline Weighted conflict & 0.213 \\
\hline Weighted cooperation & 0.207 \\
\hline \multicolumn{2}{|l|}{ Distance and Trade } \\
\hline Distance (in thousands of miles) & 4.782 \\
\hline Trade (in billions US\$) & 0.165 \\
\hline \multicolumn{2}{|l|}{ Standardizing variables } \\
\hline Capabilities ratio & 23.121 \\
\hline \multicolumn{2}{|l|}{ Democracy score } \\
\hline DEMLO & 5.516 \\
\hline DEMHI & 13.785 \\
\hline \multicolumn{2}{|l|}{ Alliances } \\
\hline Ally1 - defense pact & 0.046 \\
\hline Ally2 - neutrality & 0.001 \\
\hline Ally3 - entente & 0.064 \\
\hline \multicolumn{2}{|l|}{ Major powers } \\
\hline Maj1 - actor and target & 0.001 \\
\hline Maj2 - actor only & 0.037 \\
\hline Maj3 - target only & 0.037 \\
\hline Number of observations & 448634 \\
\hline
\end{tabular}


Table 2

Frequency of Conflict and Cooperation

\begin{tabular}{llrr}
\hline Range & \multicolumn{1}{c}{$\begin{array}{c}\text { Dyad-year obs } \\
\text { with Weighted } \\
\text { Conflict } \\
\text { in Range }\end{array}$} & $\begin{array}{r}\text { Dyad-year obs } \\
\text { with Weighted } \\
\text { Cooperation } \\
\text { in Range }\end{array}$ \\
\hline Zero & $\begin{array}{l}\text { Number } \\
\text { Proportion }\end{array}$ & $\begin{array}{r}442361 \\
0.986\end{array}$ & $\begin{array}{r}437858 \\
\text { 1-5 }\end{array}$ \\
& Number & 3222 & 0.976 \\
& Proportion & 0.007 & 6594 \\
$6-10$ & Number & 1735 & 0.015 \\
& Proportion & 0.004 & 2621 \\
$11-20$ & Number & 962 & 0.006 \\
& Proportion & 0.002 & 1306 \\
$21-40$ & Number & 578 & 0.003 \\
& Proportion & 0.001 & 658 \\
40 and above & Number & 546 & 0.001 \\
& Proportion & 0.001 & 367 \\
& & & 0.001 \\
& & & \\
\hline
\end{tabular}


Table 3

The Effect of Distance and Trade on Conflict

\begin{tabular}{|c|c|c|c|c|c|c|c|c|c|}
\hline Variable & $\begin{array}{c}\text { Parameter } \\
\text { Estimate }\end{array}$ & $\begin{array}{l}\text { Standard } \\
\text { Error }\end{array}$ & t Value & $\begin{array}{c}\text { Parameter } \\
\text { Estimate }\end{array}$ & $\begin{array}{c}\text { Standard } \\
\text { Error }\end{array}$ & t Value & $\begin{array}{c}\text { Parameter } \\
\text { Estimate }\end{array}$ & $\begin{array}{c}\text { Standard } \\
\text { Error }\end{array}$ & t Value \\
\hline Intercept & 1.2267 & 0.029 & 42.82 & 0.8377 & 0.152 & 5.52 & 0.7789 & 0.142 & 5.48 \\
\hline \multicolumn{10}{|l|}{ Distance and Trade } \\
\hline Distance (in thousands of miles) & -0.0882 & 0.003 & -27.70 & -0.1102 & 0.004 & -28.71 & -0.1002 & 0.004 & -27.84 \\
\hline Trade (in billions US\$) & -0.1357 & 0.006 & -23.21 & -0.1155 & 0.006 & -18.46 & -0.1056 & 0.006 & -17.99 \\
\hline Distance*Trade & 0.0326 & 0.001 & 23.95 & 0.0187 & 0.001 & 12.83 & 0.0195 & 0.001 & 14.22 \\
\hline \multicolumn{10}{|l|}{ Standardizing variables } \\
\hline \multicolumn{10}{|l|}{ Democracy score } \\
\hline DEMLO & 0.0093 & 0.002 & 5.73 & 0.0213 & 0.002 & 11.65 & 0.0203 & 0.002 & 11.82 \\
\hline DEMHI & 0.0282 & 0.001 & 23.48 & 0.0400 & 0.001 & 27.90 & 0.0349 & 0.001 & 25.99 \\
\hline \multicolumn{10}{|l|}{ Alliances } \\
\hline Ally1 - defense pact & 0.4858 & 0.042 & 11.50 & 0.1081 & 0.047 & 2.28 & 0.1731 & 0.045 & 3.89 \\
\hline Ally2 - neutrality & 0.1001 & 0.085 & 1.18 & -0.1948 & 0.092 & -2.12 & -0.1546 & 0.086 & -1.79 \\
\hline Ally3 - entente & 0.5371 & 0.050 & 10.66 & 0.6486 & 0.055 & 11.70 & 0.6312 & 0.052 & 12.13 \\
\hline \multicolumn{10}{|l|}{ Major powers } \\
\hline Maj1 - actor and target & -1.1641 & 0.021 & -54.59 & -1.4710 & 0.023 & -63.43 & -1.3358 & 0.022 & -61.37 \\
\hline Maj2 - actor only & 17.9100 & 0.079 & 227.35 & 16.3835 & 0.331 & 49.57 & 14.4593 & 0.310 & 46.59 \\
\hline Maj3 - target only & -0.1824 & 0.027 & -6.79 & -4.5275 & 0.322 & -14.05 & -4.1205 & 0.302 & -13.63 \\
\hline \multicolumn{10}{|l|}{ Lagged dependent variable } \\
\hline Lagged conflict & 0.0683 & 0.0003 & 251.69 & -- & & & 0.0666 & 0.0003 & 247.3 \\
\hline Actor fixed effects ${ }^{a}$ & No & & & Yes & & 8.65 & Yes & & 7.81 \\
\hline Dyad fixed effects $^{a}$ & Yes & & 20.97 & Yes & & 20.88 & Yes & & 19.84 \\
\hline Number of observations & 448634 & & & 448634 & & & 448634 & & \\
\hline R-squared & 0.2562 & & & 0.1707 & & & 0.2702 & & \\
\hline
\end{tabular}


a) t-statistic for the joint significance of the vector of categorical variables 
Table 4

The Effect of Distance and Trade on Cooperation

\begin{tabular}{|c|c|c|c|c|c|c|c|c|c|}
\hline Variable & $\begin{array}{c}\text { Parameter } \\
\text { Estimate }\end{array}$ & $\begin{array}{l}\text { Standard } \\
\text { Error }\end{array}$ & t Value & $\begin{array}{c}\text { Parameter } \\
\text { Estimate }\end{array}$ & $\begin{array}{c}\text { Standard } \\
\text { Error }\end{array}$ & t Value & $\begin{array}{c}\text { Parameter } \\
\text { Estimate }\end{array}$ & $\begin{array}{c}\text { Standard } \\
\text { Error }\end{array}$ & t Value \\
\hline Intercept & 0.6085 & 0.018 & 34.16 & 0.6123 & 0.102 & 6.01 & 0.4813 & 0.088 & 5.47 \\
\hline \multicolumn{10}{|l|}{ Distance and Trade } \\
\hline Distance (in thousands of miles) & -0.0329 & 0.002 & -16.62 & -0.0463 & 0.003 & -17.94 & -0.0326 & 0.002 & -14.66 \\
\hline Trade (in billions US\$) & -0.0259 & 0.004 & -7.14 & -0.0131 & 0.004 & -3.11 & -0.0052 & 0.036 & -1.44 \\
\hline Distance*Trade & 0.0406 & 0.001 & 47.91 & 0.0380 & 0.001 & 38.80 & 0.0293 & 0.001 & 34.63 \\
\hline \multicolumn{10}{|l|}{ Standardizing variables } \\
\hline Capabilities ratio & -0.0004 & 0.00001 & -28.10 & -0.0009 & 0.00002 & -56.96 & -0.0006 & 0.00001 & -41.86 \\
\hline \multicolumn{10}{|l|}{ Democracy score } \\
\hline DEMLO & 0.0009 & 0.001 & 0.87 & 0.0077 & 0.001 & 6.24 & 0.0020 & 0.001 & 1.92 \\
\hline DEMHI & 0.0228 & 0.001 & 30.59 & 0.0269 & 0.001 & 27.88 & 0.0173 & 0.001 & 20.81 \\
\hline \multicolumn{10}{|l|}{ Alliances } \\
\hline Ally1 - defense pact & 1.0278 & 0.026 & 39.11 & 0.7904 & 0.032 & 24.79 & 0.7404 & 0.028 & 26.89 \\
\hline Ally2 - neutrality & 1.2629 & 0.053 & 23.85 & 1.8467 & 0.062 & 29.84 & 1.2898 & 0.053 & 24.13 \\
\hline Ally3 - entente & 0.9646 & 0.031 & 30.77 & 1.2618 & 0.037 & 33.85 & 0.9523 & 0.032 & 29.59 \\
\hline \multicolumn{10}{|l|}{ Major powers } \\
\hline Maj1 - actor and target & -0.7816 & 0.013 & -58.83 & -1.3059 & 0.016 & -83.76 & -0.9024 & 0.013 & -66.85 \\
\hline Maj2 - actor only & 7.6446 & 0.052 & 148.38 & 9.9626 & 0.222 & 44.82 & 4.7668 & 0.192 & 24.78 \\
\hline Maj3 - target only & 0.3780 & 0.017 & 22.63 & -4.4273 & 0.217 & -20.44 & -3.0391 & 0.187 & -16.25 \\
\hline \multicolumn{10}{|l|}{ Lagged dependent variable } \\
\hline Lagged cooperation & 0.2881 & 0.001 & 416.98 & -- & & & 0.2723 & 0.001 & 391.45 \\
\hline Actor fixed effects $^{a}$ & No & & & Yes & & 14.35 & Yes & & 9.69 \\
\hline Dyad fixed effects $^{a}$ & Yes & & 26.27 & Yes & & 37.92 & Yes & & 26.81 \\
\hline Number of observations & 448634 & & & 448634 & & & 448634 & & \\
\hline R-squared & 0.4605 & & & 0.2968 & & & 0.4759 & & \\
\hline
\end{tabular}

a) t-statistic for the joint significance of the vector of categorical variables 
Table 5

Marginal Effects

\begin{tabular}{|c|c|c|c|c|c|c|}
\hline Percentile & Trade & Distance & $\mathrm{d}(\mathrm{coop}) / \mathrm{d}$ (trade) & $\mathrm{d}($ coop $) / \mathrm{d}($ dist $)$ & $\mathrm{d}($ conf $) / \mathrm{d}$ (trade) & $\mathrm{d}(\mathrm{conf}) / \mathrm{d}(\mathrm{d}$ is \\
\hline 10 & 0 & 1.319 & 0.0334 & -0.0326 & -0.0800 & -0.1002 \\
\hline 25 & 0 & 2.723 & 0.0746 & -0.0326 & -0.0526 & -0.1002 \\
\hline 50 & 0 & 4.513 & 0.1271 & -0.0326 & -0.0178 & -0.1002 \\
\hline 75 & 0.0083 & 6.586 & 0.1879 & -0.0324 & 0.0225 & -0.1001 \\
\hline 90 & 0.1128 & 8.523 & 0.2447 & -0.0293 & 0.0602 & -0.0980 \\
\hline
\end{tabular}

The marginal effects are computed by taking the derivative of the regression results with respect to

trade (distance) and solving across the distribution of distance (trade). 
Table 6

Instrumental Variables Estimates of the Effect of Distance and Trade on Conflict

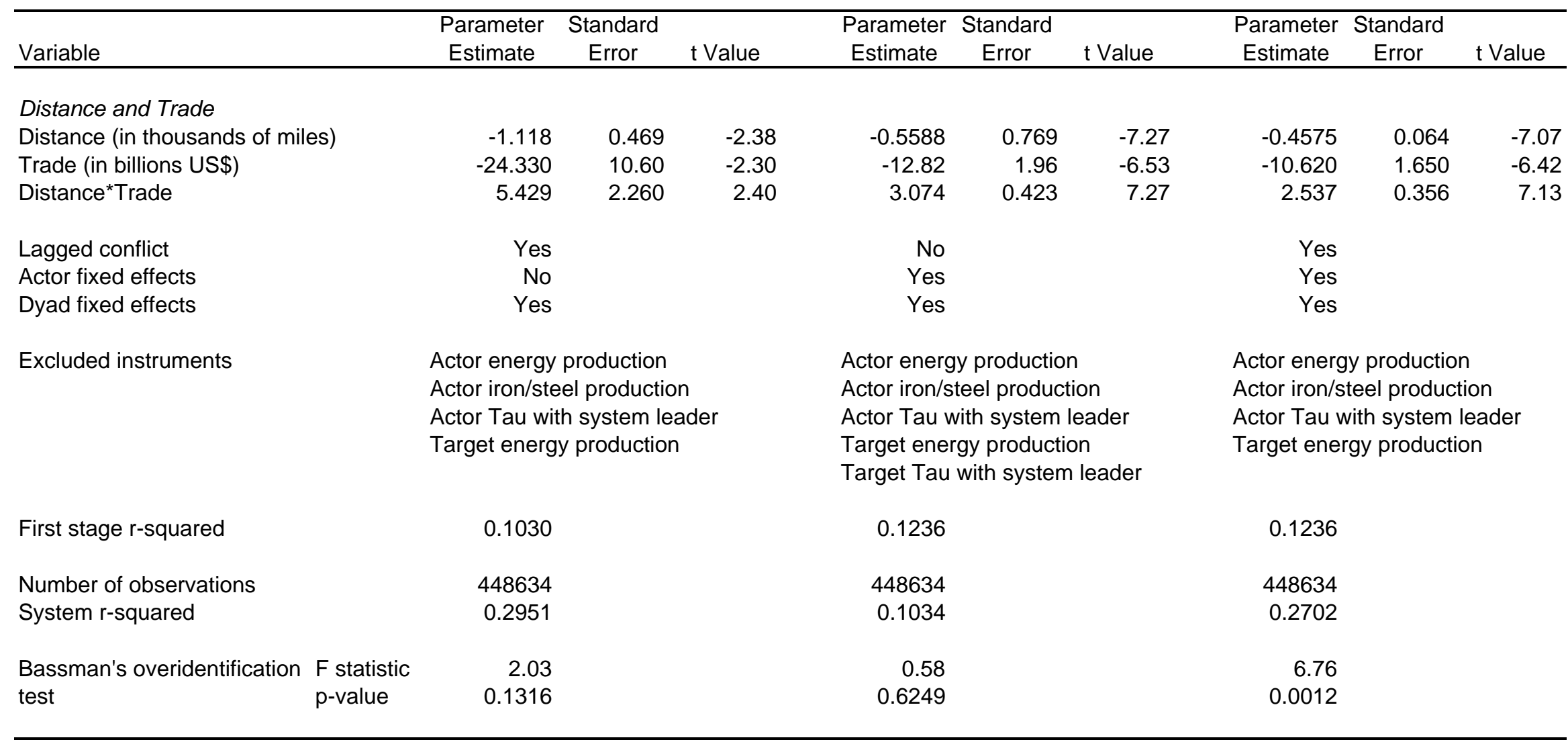


Table 7

The Effect of Distance and Trade on Conflict and Cooperation

Mundlak Combined Between and Within Effects Model

\begin{tabular}{|c|c|c|c|c|c|c|}
\hline \multirow[b]{2}{*}{ Variable } & \multicolumn{3}{|c|}{ Weighted Conflict } & \multicolumn{3}{|c|}{ Weighted Cooperation } \\
\hline & $\begin{array}{l}\text { Parameter } \\
\text { Estimate }\end{array}$ & $\begin{array}{l}\text { Standard } \\
\text { Error }\end{array}$ & t Value & $\begin{array}{c}\text { Parameter } \\
\text { Estimate }\end{array}$ & $\begin{array}{l}\text { Standard } \\
\text { Error }\end{array}$ & t Value \\
\hline \multicolumn{7}{|l|}{ Between Effects - Distance and Trade } \\
\hline Avg. Distance (in thousands of miles) & -0.0046 & 0.005 & -0.88 & -0.0487 & 0.003 & -15.36 \\
\hline Avg. Trade (in billions US\$) & -0.5172 & 0.071 & -7.31 & -1.0003 & 0.043 & -23.35 \\
\hline Avg. Distance* Avg. Trade & 0.1669 & 0.014 & 11.82 & 0.2807 & 0.009 & 32.81 \\
\hline \multicolumn{7}{|l|}{ Within Effects - Distance and Trade } \\
\hline Distance (in thousands of miles) & -0.0460 & 0.002 & -22.86 & -0.0133 & 0.001 & -10.92 \\
\hline Trade (in billions US\$) & -0.0891 & 0.005 & -18.38 & -0.0369 & 0.003 & -12.58 \\
\hline Distance*Trade & 0.0186 & 0.001 & 13.48 & 0.0449 & 0.001 & 53.62 \\
\hline R-squared & 0.0785 & & & 0.2305 & & \\
\hline
\end{tabular}

